\title{
Assessing the philosophical legacy of Kazimierz Twardowski
}

\author{
Natalia E. Sudakova - Natalia L. Sokolova - Tatyana A. Tantsura \\ - Elena L. Ryazanova - Alexander A. Evgrafov
}

DOI: $10.18355 / X L .2022 .15 .01 .16$

\begin{abstract}
As a proponent of the non-idealistic philosophy of language, more precisely, German philosophy of language, Kazimierz Twardowski was the intellectual pioneer of the theory of intentionality, truth, and predication. His aim was to develop a theory of scientific philosophy that would be characterized by vigor and exactness. While, on the one hand, Twardowski's scientific philosophy may be portrayed as strongly intellectualistic, his approach was not scientistic. It is reasonable to argue that Twardowski owed his philosophical outlook to his tutor, Franz Brentano who inspired Twardowski to make distinctions between the object and the content of a presentation within the frame of reference of mental acts' intentionality. Among his lasting contributions are (1) his formulation of the judgment-based theory of knowledge, (2) his conviction and elaboration of the concept of time-independent truth, (3) his concept of metaphilosophy, and (4) his emphasis on analysis as a viable method in philosophical deliberations.
\end{abstract}

Key words: Kazimierz Twardowski, intentionality, metaphilosophy, timeindependent truth, judgment-based theory of knowledge

\section{Introduction}

Kazimierz Twardowski (1866-1938) was born in Vienna, Austria, to Polish parents of lower nobility. His parents were wealthy enough to secure a good education for him, starting at the famous Theresian Academy in 1877. The biggest intellectual influence exerted on Twardowski came from Franz Brentano (1838-1917), a renowned philosopher and psychologist who had started his career as a Roman Catholic priest in Germany. His most formative years were arguably between 1885 to 1889 (his studies at the University of Vienna), during which period Twardowski studied under Brentano and his followers. Twardowski revered Brentano as a person, a great human character, as well as an amazing intellectual. Especially inspiring for Twardowski was Brentano's sense for a disciplined, rigorous scientific work and clarity of expression. (Lapointe et al., 2009) These then became his own principles that he continued to apply throughout his academic career. As a young doctoral student, Twardowski joined the renowned Vienna Philosophical Society, where he actively participated in rigorous debates and grew in his argumentation skills as well as the scope of scientific knowledge. He finished and defended his doctoral thesis Idee and Perception: Eine erkenntnistheoretische Untersuchung aus Descartes [Idea and Perception-An Epistemological Investigation of Descartes] in 1891 and published it later in 1892. (Twardowski, 1892) His research stays in Leipzig and Munich contributed to his academic development. Even here, though, he continued being influenced by the "Brentanians" of his time, especially Carl Stumpf (a professor in Munich). What made Twardowski famous was his habilitation thesis published in 1894 under the title Zur Lehre vom Inhalt und Gegenstand der Vorstellungen: Eine psychologische Untersuchung [On the Content and Object of Presentations-A Psychological Investigation]. (Twardowski, 1894) This work made it possible for Twardowski to receive an appointment as "Privatdocent" at his home University of Vienna for a year. However, Vienna was not to become his lasting place of service. As a rising star in philosophy and psychology with distinct Polish roots and mastery of the Polish language, Twardowski was appointed to a professorship at the University of Lvov, 
where he taught and worked until his retirement in 1930. The University of Lvov was a significant place of education for the Polish intellectuals, as it was one of only two existing Polish-speaking universities at that time. Twardowski quickly became the most prominent figure at the University, establishing his own philosophical school and influencing directly and indirectly (through hundreds of his students) the philosophical milieu in Poland and beyond. (Polec, 1979; Smith, 1989) He understood the temptation of exacting too much unnecessary 'technical' knowledge from his students, which dampened their interest and drained their creative intellectual energy. Instead, Twardowski set out to focus on what he believed were the basic foundations of sound philosophical/scientific thinking: (1) history of philosophy, (2) ethics, (3) psychology, and what he called 'core courses' in logic. (Jordan, 1963)

Besides the strict logical coherence of his philosophical argumentation, an overall clarity of his thinking, and undisputable pedagogical talent, Twardowski's success can be attributed to his approach when it came to the question of the purpose of higher education, as well as his down-to-earth, inviting a stance when it came to engaging his students and the general public. This included female students, who had been excluded from philosophical studies in many universities at that time. His lectures at Lvov University became so popular that they had to be moved from the university to the local concert hall. Thus, foundations were laid for what was to become a new philosophical movement in the Polish-speaking areas known as the 'Lvov School' (later: 'Lvov-Warsaw School'). It was not so much the content of Twardowski's thinking that defined the emerging 'Lvov School,' however. Rather, it was his overall approach to philosophy and distinct methodology. (Witwicki, 1920) As Betti correctly points out, "what all students of Twardowski had in common was not a particular set of views, but a rather distinctive attitude to philosophical problems informed by precision and clarity that they inherited from Twardowski's general conception of methodology, and which he valued most highly." (Betti, 2016) He believed that only such clear and precise philosophizing was beneficial and useful for the practical life of the people.

Due to his pedagogical and organizational/administrative duties, Twardowski had almost no time to write. Interestingly, he saw himself more as a pedagogue than an original writer. Nevertheless, he published a few works, namely Wyobrazenia i pojęcia [Images and Concepts] (Twardowski, 1898), a book published in 1898, which provided his students with a simplified version reworking of his major philosophical theories. The success and practical usefulness of this book quickly prompted him to write a modified German version Über begriffliche Vorstellungen [On Conceptual Representations] (1902) and a Polish version $O$ istoicie pojęć [On the nature of concepts] (Twardowski, 1923) in 1923. (Poli, 1996: 207)

To summarize, it is reasonable to argue that Twardowski owed his philosophical outlook to his tutor, Franz Brentano, who inspired Twardowski to make distinctions between the object and the content of a presentation within the frame of reference of mental acts' intentionality. As a proponent of the non-idealistic philosophy of language, more precisely, German philosophy of language, Kazimierz Twardowski was the intellectual pioneer of the theory of intentionality, truth, and predication. His aim was to develop a theory of scientific philosophy that would be characterized by vigor and exactness. While, on the one hand, Twardowski's scientific philosophy may be portrayed as strongly intellectualistic, his approach was not scientistic. Among his lasting contributions are (1) his formulation of the judgment-based theory of knowledge, (2) his conviction and elaboration of the concept of time-independent truth, (3) his concept of metaphilosophy, and (4) his emphasis on analysis as a viable method in philosophical deliberations. We will now turn to investigate selected emphases by Twardowski to draw (at least) preliminary contours of his philosophical legacy.

XLinguae, Volume 15 Issue 1, January 2022, ISSN 1337-8384, eISSN 2453-711X 


\section{Human speech and Logic}

Whereas Twardowski's years in Lvov were arguably more pedagogically and practically focused, his time in Vienna served as a necessary theoretical foundation for his later deliberations. Of course, this is not to say that he did not attend to the topics from his earlier studies, such as epistemological theories (theories of knowledge and truth) and the relationship between mental acts (or, more precisely, the content of mental acts) and linguistic meaning. Twardowski was always careful to clearly denote the meanings of the terms that he used and prompted his listeners to do the same. He was one of the earliest intellectuals/philosophers who understood the importance of analyzing these questions more holistically, i.e., with the help of psychology and even physiology. (Cavallin, 1997) Such a holistic approach yielded promising results and helped Twardowski establish fresh ways of approaching the relationship between a posteriori and a priori sciences (that is, inductive and deductive forms of reasoning and knowing).

The work by Twardowski, which encompasses his most developed theories on the interplay between philosophy, psychology, and physiology, is arguably his Actions and Products: Comments on the Border Area of Psychology, Grammar, and Logic (Twardowski, 1979). In this important work, Twardowski hints at what might have been perceived as obvious by logicians and other philosophers but had not often been articulated with the needed precision. "Since human speech in many cases has separate words for actions and for products (not only physical, but mental as well), logicians have long referred to mental products as something different from actions, even though they may not always have realized the difference clearly." (Twardowski, 1979: 13)

As we indicated before, Twardowski was a faithful albeit creative follower of Brentano. Regardless, the Polish philosopher was independent enough to promote his own views that often represented an extrapolation of Brentano's views. To illustrate this statement, we can compare both philosophers' core theses related to the epistemological analysis of cognitive processes: (1) whereas Brentano declares that "Every mental phenomenon has an object towards which it is directed;" (2) Twardowski reiterates the original emphasis but develops it further to include a distinction between the 'content' and the 'object' of the observed/experienced phenomenon: "Every mental phenomenon has a content and an object, and it is directed towards its object, not towards its content."

We can see that the concept of 'intentionality' serves as the foundation in both Brentano's and Twardowski's conceptual framework of the cognitive event. (Hofler, 1906) Intentionality is the basic characteristic of the cognitive agent's inner disposition. Twardowski uses the term 'disposition' in a sense formulated by Höfler (1906) in his book on psychology. Twardowski further declares that:

"Since a psychophysical product may result from several psychophysical actions, and not from a single action alone, various mental products can be expressed in it. For instance, what is expressed in a drawing may be the idea of a drawing which a person has when drawing, the idea which we want to convey through the intermediary of his drawing, his intention to convey that idea, etc. Thus, a psychophysical product expresses certain mental products directly and others indirectly with varying degrees of indirectness." (Twardowski, 1979: 19)

Human mental acts are not the same (qualitatively). Therefore, they must be carefully distinguished into distinct categories or 'classes.' There are three classes of mental acts, namely: (1) presentations, (2) judgments, and (3) affective phenomena (such as love and hate). Informed by Brentano's 'Theory of Judgment' (Brentano, 1874), Twardowski maintains that a judgment is an independent, non-contingent event, 
which cannot be reduced to a combination of presentations. (Twardowski, 1977) As an independent and distinct mental act, judgment accepts or rebuffs the object that is given by the presentation. Furthermore, "a rigorous distinction must be made between the formulation 'a psychophysical product (subject) expresses a mental product (object),' on the one hand," and similar synonymous formulation, according to which "a mental product is expressed, or finds expression, in a psychophysical product," or alternatively: "a psychophysical product is an expression of a mental product." (Twardowski, 1979: 20) This distinction may not appear crucial at first sight. However, it proves to be useful in situations when humans need to deal with common misconceptions and misunderstandings related to a given phenomenon in contrast to human affective responses to the same phenomena. As an example, we can consider the lack of distinction that human agents often exhibit with it comes to evaluating the relationship between human emotions (the affective side of a human person) and music. "For, while everyone agrees that emotions (and thoughts) experienced by the composer at the time of composing can be expressed in a musical work, it does not in the least follow that that work expresses those emotions." (Twardowski, 1979: 20)

Twardowski showed his creative genius and relative independence from Brentano in his treatment of the so-called 'immanent object' in relation to 'the object of a presentation.' He postulated the need to make a distinction between object and content of a presentation, clarifying and somewhat correcting/complementing Brentano's original position. When it comes to the question of who could possibly have served as an inspiration to Twardowski for this distinction, Bernard Bolzano (1781-1848) emerges as the most likely culprit. (Skolimowski, 1967) If it is true, it is an interesting observation because although Bolzano's views had been known for about one hundred years prior to Twardowski, they had not been taken seriously by Brentano and his followers. In any case, Twardowski managed to produce a viable mixture of Bolzano's and Brentano's ideas pertaining to human mental acts. As a result, he postulated that regardless of the quality or commonality of object, there can be no presentations unless each presentation is linked to an object.

According to Twardowski, linguistic terms are then indispensable counterparts of presentations. In some cases, content plays the role of object; in other cases it does not. Meaning is, in any case, something distinct, mentally present, individual. The mental sphere of an individual constitutes the necessary basis for the semantic sphere of content and object. This, however, does not overcome the ambiguity of the verb "to mean," as is stated in the text below:

"When we say that a word means something, we intend to convey that it has a meaning. The verb 'to mean' interpreted in this sense corresponds to the Latin verb 'significare' and to the German verb 'bedeuten'. Instead of saying that a word or, more generally, a psychophysical product, means something, we may say that it has a meaning, and also that it comprises a meaning, that a meaning is connected with it, that a meaning is inherent in it, that it expresses a meaning. (...) We also say that psychophysical products denote something; this is to say they denote the outer objects of those actions from which those psychophysical objects result. Thus, we say, with respect to words, that they not only mean something, but also denote something, for some words come into existence as a result of names being given to objects. Hence the psychophysical product of this action is a name, i.e., a word whose meaning is the representation of a given object. At the same time, a name or a word denotes (mentions) that object. Thus, 'Sophro-niscus' son' expresses a concept which is its meaning, but which also mentions a certain person. Likewise, the word 'triangle' expresses a concept, which is its meaning, and denotes 
(mentions) all the objects that come within that concept." (Twardowski, 1979: 24)

To understand Twardowski's legacy for understanding the relationship between object and presentation, we need to notice his view of the ontological status of the key aspects of a presentation. These include: (1) act, (2) content, and (object) and each of them, according to the Polish philosopher, enjoys a distinct ontological status. (Smith, 1989) Whereas the content and the act exist permanently, being bonded together in the mental act of the thinking agent, the object does not always exist. Furthermore, Twardowski asserts that in contrast to the act, the content is contingent upon the act, and therefore its very existence is contingent upon the act. His theory of intentionality cannot be comprehended without these ontological distinctions. Furthermore, Twardowski's theory postulates that objects do not need to exist in the real world to have specific properties ascribed to them. This is true because existing is not the same (ontologically) as being presented. Finally, Twardowski's theory of Content and Object should not be seen as a self-standing, independent philosophical theory but rather as an integral part of a larger whole. Twardowski meant for philosophers to investigate the meaning and implication of his contribution to understanding the relationship between Content and Object as part of a more complex endeavor that would include reflecting on an appropriate theory of judgment and a theory of concepts.

\section{The Tasks of Scientific Ethics}

When speaking of the tasks of scientific ethics, Twardowski maintains that axioms and/or facts are an indispensable foundation for scientific ethics. "To be scientific, ethics must not include statements that are derived in any manner other than ethical reasoning from axioms or facts." (Twardowski, 1973: 154) This does not mean, however, that ethical reasoning will establish the appropriate rules of conduct and norms, let alone morality. Established norms and rules of behavior must be posited through a qualitatively different order of reasoning, as "no science at all can give rules."

"Contrary to the common view, no science at all can give rules. Science says merely what is, and how it is, but not what ought to be. Norms, i.e. rules of conduct, follow not from theoretical studies but from the practical applications of the theoretical results. Hygiene, for instance, indicates physical movement as an indispensable condition of maintaining health; but the norm 'We ought to make physical exercises' originates from our concern with the important aim of maintaining our health." (Twardowski, 1973: 154)

Therefore, according to Twardowski, rules of conduct follow from the practical applications of theoretical scientific conclusions. Such practical applications are informed by the existing notions of what is good or expedient - in this case, the notion of 'maintaining our health.' All human agents have certain practical objectives on their mind, i.e., they are intentionally 'bent' on achieving given objectives. (Twardowski, 1974: 22-24) If this is true, the question remains 'what is the relationship of scientific ethics to the emergence and implementation of practical objectives as part of the cognitive mental process?' What should be the content of scientific ethics if we do not wish to reduce it to mere 'descriptive ethics'? Twardowski wrestled with this problem until he realized that not theoretical, abstract scientific thinking would ever have arisen had it not been for the emergence of intentional thinking and behavior among human agents. Besides, intentionality, as a part of the mental processes in humans, led to conflicting situations among human individuals, which required the development of a distinct type of reflection - ethical reflection. Twardowski points out that "The fact that these conflicts happen to be of different intensities furnishes the object of study for scientific ethics; it is to study the 
conditions in which those conflicts are at their smallest." The science of ethics is thus directly dependent on analyzing human experience for its theoretical propositions. For it is "by analysing and generalizing facts provided by experience, scientific ethics will arrive (partly it has already arrived) at a number of purely theoretical propositions." (Twardowski, 1973: 154) There are other forces or 'factors,' vested with a nonnegligible executive power, that concern themselves with the pursuit of concrete, practical objectives. "Such factors are most often educators in the broad sense, i.e., parents, teachers in the case of individuals, and religion and law in the case of societies." (Twardowski, 1973: 154)

It is easy to notice that Twardowski refuses to limit the task of philosophy to purely abstract scientific reasoning. Instead, he wishes to link the theoretical/logical constructs of the philosophers with the daily decisions of people by showing the inevitable practical implications of scientific thinking. Hence his reference to 'factors,' i.e., the 'executive forces' in each given society and/or interpersonal relationship. These 'factors' can be individual/personal or institutional (such as religious, state, or cultural/social institutions). On the individual level, parents and teachers play the most prominent role.

Life's complexities and challenges have since the dawn of first human civilizations required to make viable decisions when it comes to shaping human interactions and making sure that a given human society stays orderly and sustainable. Therefore, the next question that requires attention revolves around the timing of the emergence of scientific investigations. Twardowski realizes that it would have been unfeasible for human individuals and societies to wait until 'theoretical investigations' of scientists provide the necessary theoretical background for informed decision-making regarding customs, morals, and procedures governing human interactions. Instead, the prescientific human societies had to rely on what Twardowski calls 'social instinct,' the most important element of which is 'ethical instinct.' This 'social/ethical' instinct plays such a crucial role in human societies that Twardowski labels it 'social selfpreservation instinct.'

"But the educators of individuals and societies could hardly wait till ethics would provide for them the results of theoretical investigations from which they could derive rules serving their appropriate ends. Those ends, which are ultimately reduced to securing the coexistence of individuals and social groups, had been calling for implementation long before any attempts at scientific ethics have first been made. Therefore the educators tended to implement those ends by means of norms created on the strength of a social instinct, especially of an ethical instinct, which can be called the social self-preservation instinct." (Twardowski, 1973: 155)

It is not common for a scientist, let alone a scientist with an excellent reputation of being logical, coherent, and methodologically strict - such as Kazimierz Twardowski - to appeal to instinct as a useful epistemological and ethical tool. In this sense, in any case, Twardowski was ready to concede the limitations of hard sciences without lapsing into emotional mysticism or irrationalism. The concept of scientific knowledge/investigation in Twardowski was, on the one hand, utterly intellectual, while on the other hand, was not reducible to scientism as an ideology (either in a methodological or ontological sense). "If we analyze science, we come to the conclusion that it is a complex of judgments that satisfy certain conditions, and that these judgments are either based on concepts or themselves contained in concepts." These concepts are, so to speak, 'pre-scientific,' being themselves derived from or having arisen from a vast array of assemblages of human experiences. "In this way numerous rules of conduct were created, in habits and customs, in the ethics of personal relations and in the precepts of public opinion, in common law and later in

XLinguae, Volume 15 Issue 1, January 2022, ISSN 1337-8384, eISSN 2453-711X 
positive law, and in religious precepts. Such numerous, sometimes conflicting norms existed before the appearance of scientific ethics. (Similarly, there had been numerous precepts concerning the protection of health in customs and in rituals still before scientific hygiene was created)." (Twardowski, 1973: 155) Ethics of personal relationships emerges from day-to-day human interactions based on that which secures and furthers such interactions. Habits and customs arise from the need to set rules and norms for human communities so that each human individual knows what is expected of him or her. Intuitively perceived common law only over time morphs into positive law, which becomes institutionalized and enforced by a government. Religious customs and precepts play a similar role, though the alleged origin of these is some sort of a 'divine revelation' (as seen from the perspective of the insiders/members of the given religious community). Nevertheless, it is through the exercise of social instinct that humans and human communities learned to live together and thrive.

This does not mean, according to Twardowski, that scientific investigation and reasoning are no longer valid or useful. On the contrary, it provides the much-needed and often lacking clarity. It offers "the foundation for overcoming the possible conflicts between the norms guiding our lives." While ignored and underappreciated in former times, the discoveries and results of scientific thinking, according to Twardowski, will be impossible not to listen to" (Twardowski, 1973: 155) in the days to come.

When it comes to metaphysics, Twardowski initially considered metaphysics as a part of science - a special part, to be sure, that deals with unique topics, such as the existence and nature of God, immortality of the soul, or the freedom of human will. "Later (after 1902), when he rejected the thesis about the scientific nature of broadly understood metaphysics in favor of metaphysics on a narrower range of issues (general theory of subject and relation), he still rejected most of the theses of radical scientism." (Lukasiewicz, 2021: 352) However, metaphysics still belongs into the realm of philosophy, according to Twardowski. In its claim on knowledge, "it can use the principle of introspective inference, deductive methods, including axiomatic and abductive methods (inference to the best explanation)." (Lukasiewicz, 2021:358)

\section{Conclusion}

Kazimierz Twardowski left a lasting legacy as a philosopher, pedagogue, scientist, and academic organizer. His unique approach to non-idealistic philosophy of language with its ingenious theory of intentionality, truth, and predication was foundational for the emergence of the Lvov-Warsaw School of Polish philosophy that shaped much of the academic life in Poland between WWI and WWII and even during the period after WWII. His emphasis on vigor and exactness in employing scientific methodology in his philosophical and psychological deliberations continues to provide inspiration to academicians today. His ability to interweave and integrate knowledge from a diverse array of scientific disciplines, as we can observe in his work on the relationship between philosophy, physiology, and psychology entitled "Psychology vs. Physiology and Philosophy (1897)" (Twardowski, 1999: 41-64), is not only commendable but also worth following today. Twardowski's treatment of the relationship between a priori and a posteriori sciences (deductive and inductive sciences, respectively) helped develop a more robust and complex scientific method. Due to his indisputable inclination towards 'scientific investigations' in contrast to non-scientific speculations, one often presumes that Twardowski was a proponent of classical scientism. This, however, is far from the truth. Although Twardowski's scientific philosophy may be portrayed as strongly intellectualistic, his approach was not scientistic in an ideological, reductionist sense. Quite on the contrary, the Polish philosopher had a place for intuition and even a qualified version of 'metaphysics' in his philosophical outlook. Furthermore, though it may not be obvious at first glance, 
Twardowski had an acute sense of wholeness based on an anti-relativistic notion of truth. This may not be initially obvious because Twardowski comes across as a 'down-to-earth' philosopher who seeks to emphasize practical implications of his fractional (i.e., small in scope) theories. His objection to relativism when it comes to an understanding and defining truth stems from precisely this desire to render his philosophical deliberations viable and useful. If, as Twardowski believes, we give up on the notion of truth as a non-relativistic category, we lose the ability to construct a solid ethical substrate that we can claim is based on scientific principles. In such a scenario, we are relegated to constantly fighting other, competing groups of people who devise their own rules and principles on equally non-scientific grounds therefore, the stronger is bound to win (not the one closer to truth). Finally, based on our analysis of the affinity of thought between Twardowski and Brentano we can reasonably argue that Twardowski owed much of his philosophical outlook to his tutor, Franz Brentano. Brentano not only inspired Twardowski to make distinctions between the object and the content of a presentation within the frame of reference of mental acts' intentionality but also taught him to be unrelenting and scientifically honest in employing his intellect in a scientific, methodologically sound pursuit of truth that builds up human societies.

\section{Bibliographic references}

Betti, A. (2016). "Kazimierz Twardowski" in E. Zalta (ed.) Stanford Encyclopedia of Philosophy (Fall 2021 edition), available https://plato.stanford.edu/archives/fall2021/entries/twardowski/.

Brentano, F. (1874). Psychologie vom empirischen Standpunkt, 2 vols. Leipzig: Duncker and Humblot.

Cavallin, J. (1997). Content and object: Husserl, Twardowski and psychologism (Vol. 142). Dordrecht/London: Kluwer Academic Publishers.

Hofler, A. (1906). Grundlehren der Logik und Psychologie: Mit einem anhange: Zehn Lesestücke aus philosophischen Klassikern. Berlin: G. Freytag.

Jordan, Z. (1963). Philosophy and ideology. The development of philosophy and Marxism-Leninism in Poland since the Second World War. Dordrecht: Reidel.

Lapointe, S., Wolenski, J., Marion, M., \& Miskiewicz, W. (2009). The golden age of Polish Philosophy: Kazimierz Twardowski's philosophical legacy (16). Springer Science \& Business Media.

Lukasiewicz, D. (2021). “Analiza relacji między filozofią, nauką a światopoglądem w ujęciu Twardowskiego" in J. Jadacki (ed.), Rozum i wola: Kazimierz Twardowski I jego wplyw na ksztalt kultury polskiej XX wieku. Lublin: Wydawnictwo Academicon, 347-384.

Pelc, J. (1979). Semiotics in Poland 1984-1969. Warszawa: Polish Scientific Publishers.

Poli, R. (1996). Kazimierz Twardowski (1866-1938). In The School of Franz Brentano Dordrecht: Springer, 207-231. https://doi.org/10.1007/978-94-015-8676-4_8 Skolimowski, H. (1967). Polish analytical philosophy. London: Routledge and Kegan. Smith, B. (1989). "Kasimir Twardowski: An essay on the borderlines of ontology, psychology and logic" in K. Szaniawski (ed.) The Vienna Circle and the LvovWarsaw School. Boston/London: Kluwer, 313-373.

Twardowski, K. (1892). Idee und Perception. Eine erkenntnis-theoretische Untersuchung aus Descartes, Wien: Hölder.

Twardowski, K. (1894). Zur Lehre vom Inhalt und Gegenstand der VorstellungenEine psychologische Untersuchung. Wien: Hölder.

Twardowski, K. (1898). Wyobrażenia i pojęcia (Images and Concepts). Lvov: Altenberg.

XLinguae, Volume 15 Issue 1, January 2022, ISSN 1337-8384, eISSN 2453-711X 
Twardowski, K. (1923). O istocie pojęć (On the Essence of Concepts), Lwów: Nakładem PTF.

Twardowski, K. (1973). “O zadaniach etyki naukowej” in Etyka, vol. 12. Warszawa: Państwowe Wydawnictwo Naukowe, 125-155.

Twardowski, K. (1974). Wykłady z etyki. Warszawa: Państwowe Wydawnictwo Naukowe.

Twardowski, K. (1977). On the content and object of presentations. Hague: Nijhoff.

Twardowski K. (1979) Actions and Products. Comments on the Border Area of Psychology, Grammar, and Logic. In: Pelc J. (eds) Semiotics in Poland 1984-1969. Synthese Library (Studies in Epistemology, Logic, Methodology, and Philosophy of Science), vol 119. Springer, Dordrecht. https://doi.org/10.1007/978-94-009-9777-6_4. Twardowski, K. (1999). On actions, products and other topics in philosophy (Vol. 1). Rodopi.

Witwicki, W. (1920). Kazimierz Twardowski. Przegląd Filozoficzny, 23, IX-XIX.

Words: 4932

Characters: 33572 (18,70 standard pages)

Prof. Natalia E. Sudakova, Dr.

UNESCO Chair, Russian Presidential Academy of National Economy and Public Administration (RANEPA)

82 Vernadskiy Prospect

119571 Moscow

Russia

sudakovane@bk.ru

Assoc. Prof. Natalia L. Sokolova, PhD

Peoples' Friendship University of Russia (RUDN University)

6 Miklukho-Malkaya Street

117198 Moscow

Russia

n.sokolova@rudn.ru

Assoc. Prof. Tatyana A. Tantsura,

Financial University under the Government of the Russian Federation

Leningradsky Prospekt, 49

125993 Moscow

Russia

ttancyra@yandex.ru

Assoc. Prof. Elena L. Ryazanova, PhD

I.M. Sechenov First Moscow State Medical University (Sechenov University)

8 Trubetskaya Street,

119991 Moscow

Russia

scarobey64@mail.ru

Assoc. Prof. Alexander A. Evgrafov, PhD

I.M. Sechenov First Moscow State Medical University (Sechenov University)

8 Trubetskaya Street,

119991 Moscow

Russia

evgrafov_a_a@staff.sechenov.ru 